\title{
Impact of Data Mining Technique in Education Institutions
}

\author{
Mr. Bhushan Bandre, Ms. Rashmi Khalatkar \\ Research Scholar, Department of Computer Science and Engineering \\ D.M.I.E.T.R. Wardha Maharashtra India \\ Bhushanbandre47@gmail.com
}

\begin{tabular}{|l|l|}
\hline Article History & \multicolumn{1}{|c|}{ Abstract } \\
$\begin{array}{l}\text { Article Submission } \\
10 \text { February 2015 } \\
\text { Revised Submission } \\
27 \text { April 2015 } \\
\text { Article Accepted }\end{array}$ & $\begin{array}{l}\text { Major decision making process using large amount of data can be done by various } \\
\text { techniques using data mining. In education sectors various data mining techniques } \\
\text { are implemented to analyze the student's data from the admission process itself. Due } \\
\text { to large number of educational institution in India, excellence becomes a major } \\
\text { Article Published } \\
\text { parameter for the institutions to grow and with stand. Nowadays education } \\
\text { institutions use data mining techniques to show their excellence. The main objective } \\
\text { of this work to present an analysis of individual semester wise results of engineering } \\
\text { college students using different techniques of data mining. Here we used different } \\
\text { classification algorithms like decision tree, rule based, function based and Bayesian } \\
\text { algorithms to analyze the semester results and comparison is made by considering } \\
\text { parameters like accuracy and error rate. Our output shows the most suited algorithm } \\
\text { for analyzing data in educational institutions. } \\
\text { Keywords: Data mining, Error rate, Accuracy, Optimization }\end{array}$ \\
\end{tabular}

\section{Introduction}

Secondary and higher education in India has gained significance growth for last few years. Due to more number of institutions and different courses the competition has increased among them in various aspects such as infrastructure, faculty, admissions, results and placements etc. The education regulatory committee stream lined some guidelines with respect to infrastructure, faculty and other required resources. Many new technologies were emerged in order to analyze and work with data, because data management is the key element for the success in any organization including educational organization. By proper data management the results of institution can be improved rigorously .A encouraging field to this objective is the usage of Data Mining technique [1]. Data mining is already well emerged in wholesale and retail business applications, but its entry in secondary and higher education is relatively less. In education sector, data mining is going to prove its best for the solutions in various parameters related to institutions growth [2].

The whole objective is solving all problems in education field and to improve process using various statistical techniques and data mining algorithms [3]. Educational data Mining an excellent practice used for prediction of student performance, analytics ,admissions, student modeling and grouping of students etc.

Educational Data Mining is targeted on various developing methods elaborate the uniqueness of large dataset from educational institutions. By using data mining it provides better environment for the students for their excellence in educating themselves in various things like studies, self-development and job opportunities. Data Mining is the process to converting data from education institutions to required information which can be used by faculty, administration staff, parents and researchers [4]. In education system, the prediction and explanation of performance day by day and monitoring the improvement is very important [5]. 


\section{Related Work}

Recent taxonomy encompasses all four types and focus on various applications of educational data mining to internet and web data [6]. The starting point of any study is Statistics and visualization which cannot be formally corrected. The following two categories are normal things which is found to be in data mining projects while the last category is an extension of data text data which is related to web [7].

The data mining in education institutions [8] has four strategies first is to improve students' model second is identify models for the knowledge structure third is pedagogical support by software and scientific methods about learning and learners. Predictive modeling techniques are used to understand the correlations in existing data. Results of above method will help for students associated with new registration and long term education process of students [9]. The well-known techniques such as clustering, decision tree and association is used to improve student's performance in secondary and higher education process. The overall outcome of this process can be explicitly used by faculty, curriculum designer who decides the courses for the students. This method used by educational course planner to have more relevant advance strategies on emerging technologies [10].

Data mining allows the machine learning algorithms for the automated discovery of new patterns and trends in the obtained data. Hence survey concludes data mining in education helps in identify students, behavior, and understanding learning outcomes of the engineering students.

\section{Proposed Data path Designs}

Initially before starting any process in data mining techniques, reliable data should be available. In order to collect data we are using spread sheet in Google. Even though lot methods are implemented to collect data, but the easiest and cost efficient method is Google spread sheet. An expert team is involved to prepare the required questionnaires to easily collect the data from the students. All the questionnaires are sent to the engineering students from a rural based engineering college in Tamil Nadu. The basic framed questions will cover data such as secondary percentage, semester wise percentage, training undergone, online course attended, skill development modules attended etc. The detailed questions will acquire data such as demographic, skill set and learning behavior.

In our analysis we used SPSS and WEKA online tools. WEKA is an education data mining analysis tool and is used to analyze different classification algorithms and it can also compare the performance of these algorithms based on various parameters. SPSS is well known statistical tool to identify the parameters of student's performance enhancement. Here different classification algorithm is implemented in student's data base by using various parameters of algorithms for efficient analysis. To improve the accuracy data is tested in 20 fold cross validation. The various algorithms which were implemented on our WEKA tools are NBDT, Decision Tree (J48), J Rip, One R, Random Forest, Random Tree, REP Tree, , Simple Logistic and Zero R. 


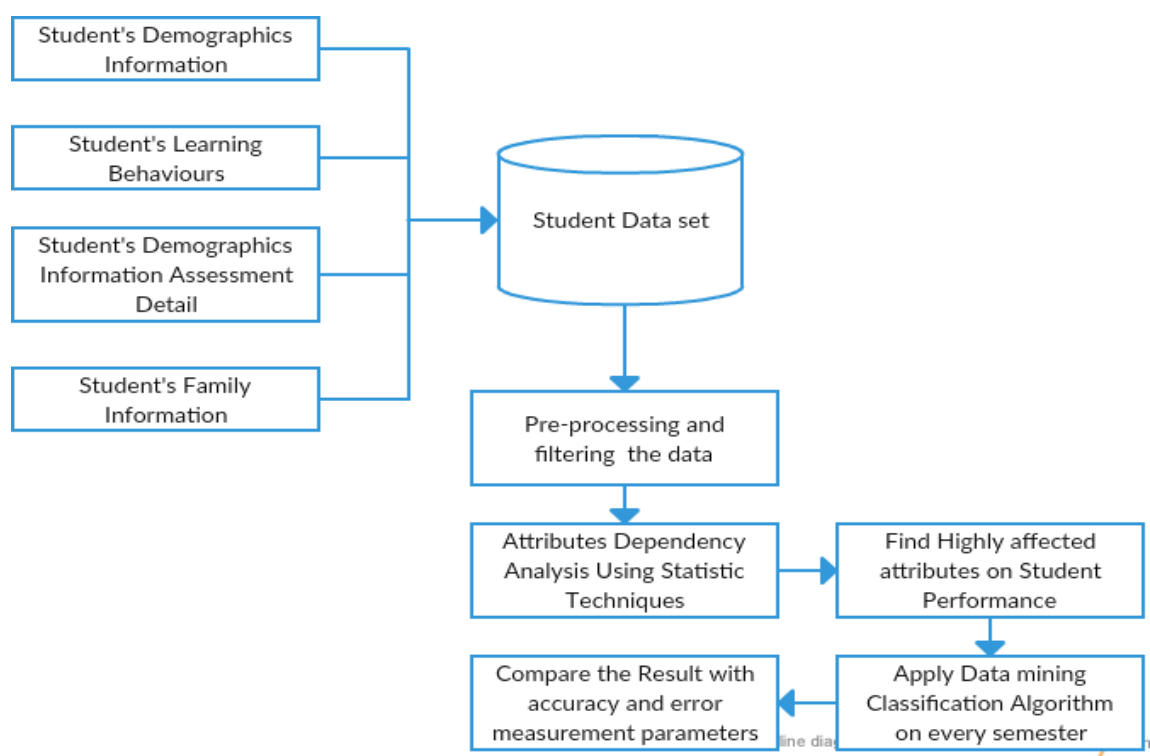

Fig 1: Proposed Research model

\section{Implementation and Analysis}

The student parameters are analyzed based on the following stages:

Stage1: Collecting the information of the students.

Stage 2: preprocessing and optimization of the data.

Stage 3: Statistical techniques are applied to find students affected parameters.

Stage 4: Data mining techniques like Classification, Clustering, and Association is applied on student's data set.

Stage 5: Finding out the optimized data set.

TABLE 1: Student Parameters

\begin{tabular}{|c|c|c|}
\hline PARAMETERS & DATA & VALUES WITHOUT ERROR \\
\hline General & Nominal & Poor, Good, Excellent \\
\hline Overall attendance & Nominal & Poor, Good, Excellent \\
\hline Hour attendance & Nominal & Poor, Good, Excellent \\
\hline Day attendance & Nominal & Poor, Good, Excellent \\
\hline Week attendance & Nominal & Poor, Good, Excellent \\
\hline Month attendance & Nominal & Poor, Good, Excellent \\
\hline College Internal marks & Nominal & Excellent, Good, Average,Fail \\
\hline College Assignment marks & Nominal & Excellent, Good, Average, Fail \\
\hline Extracurricular activities & Nominal & Nil, Average, Good, Excellent \\
\hline Practical Marks & Nominal & Excellent, Average, Good \\
\hline Theoretical marks & Nominal & Fail, Pass \\
\hline Project Marks & Nominal & Fail, Pass \\
\hline
\end{tabular}




\begin{tabular}{|c|l|c|}
\hline Previous semester \% & Nominal & All clear, Backlogs \\
\hline Name of the subject & Nominal & Compiler Design \\
\hline Affiliated Theory Marks & Nominal & Pass, Fail \\
\hline Affiliated Practical Marks & Nominal & Pass, Fail \\
\hline Attendance & Nominal & Poor, Average, Good \\
\hline Faculty Performance $\%$ & Nominal & Poor, Average, Good \\
\hline Result \% & Nominal & Poor, Good, Excellent \\
\hline Semester result \% & Nominal & Poor, Average, Good \\
\hline
\end{tabular}

Th multiple regressions were run to find seventh semester results from independent variables. These variables statistically predicted results of seventh semester, $\mathrm{F}(51,5217)=736.946, \mathrm{p}<.0002$, In order to retain all variables level is $<0.0003$ and discard data which is $>0.0002$ from the model.

TABLE 2: SPSS analysis of student's performance

\begin{tabular}{|l|l|}
\hline$\%$ in HSC & Assignment Marks \\
\hline$\%$ in first year & Subject Practical Knowledge \\
\hline$\%$ in second year & Subject Theory Marks \\
\hline Attendance & Project \\
\hline Internal Marks & Previous Semester Marks \\
\hline Extra Curriculum & Conferences \\
\hline
\end{tabular}

Here we used various classification algorithms like J48, Bayes Net, Multi-layer perception, Naïve Bayes, One R, Rep Tree, Decision stump, Logistic Regression, and sequential minimal optimization. Then results are compared with algorithms using WEKA tool. The comprative result is postulated.

TABLE 3: Semester wise data to build the model by various classifiers

\begin{tabular}{|c|l|l|l|l|l|l|l|l|l|}
\hline Semesters & J48 & LS & MLP & BN & DS & ONE R & NB & SMO & LR \\
\hline I & 0.12 & 0.78 & 0.9 & 1.21 & 2.13 & 0.012 & 0.126 & 0.156 & 0.245 \\
\hline II & 0.0402 & 0.102 & 0.8202 & 2.3302 & 55.4502 & 0.023 & 0.154 & 0.125 & 0.235 \\
\hline III & 0.0525 & 0.125 & 0.8325 & 2.1425 & 55.4625 & 0.032 & 0.185 & 0.124 & 0.214 \\
\hline IV & 0.043 & 0.119 & 0.8299 & 2.3399 & 55.4599 & 0.12 & 0.121 & 0.145 & 0.265 \\
\hline V & 0.042 & 0.103 & 0.8273 & 2.0373 & 55.4573 & 0.1235 & 0.112 & 0.165 & 0.222 \\
\hline VI & 0.02 & 0.12 & 0.9 & 2.41 & 56.43 & 0.225 & 0.1325 & 0.144 & 0.213 \\
\hline VII & 0.023 & 0.01 & 0.08 & 2.04 & 55.23 & 0.225 & 0.164 & 0.178 & 0.214 \\
\hline VIII & 0.01 & 0.03 & 0.02 & 2.10 & 55.21 & 0.54 & 0.125 & 0.111 & 0.298 \\
\hline $\begin{array}{l}\text { Mean } \\
\text { Value }\end{array}$ & 0.0326 & 0.1234 & 0.8183 & 2.3565 & 55.881 & 0.129 & 0.156 & 0.173 & 0.242 \\
\hline
\end{tabular}


TABLE 4: Semester wise corrected classified instance by various classifiers

\begin{tabular}{|c|l|l|l|l|l|l|l|l|l|}
\hline Semesters & J48 & LS & MLP & BN & DS & ONE R & NB & SMO & LR \\
\hline I & 89.42 & 81.27 & 50.64 & 87.89 & 87.07 & 87.7 & 68.9 & 87.1 & 77.81 \\
\hline II & 89.12 & 86.45 & 59.64 & 87.41 & 82.26 & 87.4 & 72.9 & 85.8 & 82.7 \\
\hline III & 89.29 & 87.65 & 61.64 & 87.41 & 83.76 & 88.4 & 74.9 & 86.8 & 83.7 \\
\hline IV & 89.95 & 87.65 & 61.64 & 88.01 & 83.16 & 88.4 & 74.9 & 87.8 & 84.7 \\
\hline V & 89.05 & 87.65 & 62.04 & 88.41 & 84.66 & 88.4 & 74.5 & 87.8 & 84.7 \\
\hline VI & 89.17 & 88.27 & 49.94 & 8.49 & 79.27 & 88.7 & 69.9 & 88.1 & 79.1 \\
\hline VII & 89.01 & 88.00 & 45.02 & 97.98 & 88.23 & 88.00 & 85.20 & 88.32 & 95.02 \\
\hline VIII & 89.02 & 87.01 & 59.32 & 97.56 & 89.32 & 98.12 & 84.02 & 86.25 & 96.25 \\
\hline $\begin{array}{l}\text { Mean } \\
\text { Value }\end{array}$ & 89.24 & 86.95 & 58.47 & 87.42 & 81.54 & 88.15 & 72.30 & 86.12 & 81.60 \\
\hline
\end{tabular}

TABLE 5: Semester wise kappa statistical rate

\begin{tabular}{|c|c|c|c|c|c|c|c|c|c|}
\hline Semesters & J48 & LS & MLP & BN & DS & ONE R & NB & SMO & LR \\
\hline I & 0.042 & 0.103 & 0.8273 & 2.0373 & 55.45 & 0.123 & 0.112 & 0.165 & 0.222 \\
\hline II & 0.02 & 0.12 & 0.9 & 2.41 & 56.43 & 0.225 & 0.1325 & 0.144 & 0.213 \\
\hline III & 0.023 & 0.01 & 0.08 & 2.04 & 55.23 & 0.225 & 0.164 & 0.178 & 0.214 \\
\hline IV & 0.01 & 0.03 & 0.02 & 2.10 & 55.21 & 0.54 & 0.125 & 0.111 & 0.298 \\
\hline V & 0.02 & 0.78 & 0.9 & 1.41 & 2.43 & 0.012 & 0.126 & 0.156 & 0.245 \\
\hline VI & 0.0402 & 0.102 & 0.8202 & 2.3302 & 55.45 & 0.023 & 0.154 & 0.125 & 0.235 \\
\hline VII & 0.0525 & 0.125 & 0.8325 & 2.1425 & 55.46 & 0.032 & 0.185 & 0.124 & 0.214 \\
\hline VIII & 0.043 & 0.119 & 0.8299 & 2.3399 & 55.45 & 0.12 & 0.121 & 0.145 & 0.265 \\
\hline Mean Value & 0.0126 & 0.2134 & 0.7983 & 2.2465 & 55.58 & 0.139 & 0.166 & 0.153 & 0.212 \\
\hline
\end{tabular}

TABLE 6: Semester wise Mean Absolute Error classifiers

\begin{tabular}{|c|r|c|c|c|c|c|c|c|c|}
\hline Semesters & \multicolumn{1}{|l|}{ J48 } & LS & MLP & BN & DS & $\begin{array}{l}\text { ONE } \\
\text { R }\end{array}$ & NB & SMO & LR \\
\hline I & 0.0634 & 0.060 & 0.067 & 0.023 & 0.154 & 0.125 & 0.103 & 0.8273 & 2.0373 \\
\hline II & 0.0934 & 0.070 & 0.097 & 0.032 & 0.185 & 0.124 & 0.12 & 0.9 & 2.41 \\
\hline III & 0.1034 & 0.080 & 0.107 & 0.12 & 0.121 & 0.145 & 0.01 & 0.08 & 2.04 \\
\hline IV & 0.1134 & 0.090 & 0.117 & 0.1235 & 0.112 & 0.165 & 0.03 & 0.02 & 2.10 \\
\hline V & 0.1234 & 0.100 & 0.127 & 0.225 & 0.1325 & 0.144 & 0.78 & 0.9 & 1.41 \\
\hline VI & 0.0734 & 0.060 & 0.077 & 0.225 & 0.164 & 0.178 & 0.102 & 0.8202 & 2.3302 \\
\hline VII & 0.098 & 0.07 & 0.054 & 0.54 & 0.125 & 0.111 & 0.125 & 0.8325 & 2.1425 \\
\hline VIII & 0.09 & 0.07 & 0.043 & 0.129 & 0.156 & 0.173 & 0.119 & 0.8299 & 2.3399 \\
\hline Mean Value & 0.0950 & 0.077 & 0.098 & 0.023 & 0.154 & 0.125 & 0.2134 & 0.7983 & 2.2465 \\
\hline
\end{tabular}


TABLE 7: Semester Root Mean Squared Error Rate classifiers

\begin{tabular}{|c|c|c|c|c|c|c|c|c|c|}
\hline Semesters & J48 & LS & MLP & BN & \multicolumn{1}{c|}{ DS } & \multicolumn{1}{l|}{ ONE } & NB & SMO & LR \\
\hline I & 0.126 & 0.156 & 0.245 & 0.042 & 0.103 & 0.2 & 0.060 & 0.067 & 0.125 \\
\hline II & 0.154 & 0.125 & 0.235 & 0.02 & 0.12 & 0.22 & 0.070 & 0.097 & 0.154 \\
\hline III & 0.185 & 0.124 & 0.214 & 0.023 & 0.01 & 0.21 & 0.080 & 0.107 & 0.165 \\
\hline IV & 0.121 & 0.145 & 0.265 & 0.01 & 0.03 & 0.23 & 0.090 & 0.117 & 0.134 \\
\hline V & 0.112 & 0.165 & 0.222 & 0.02 & 0.78 & 0.28 & 0.100 & 0.127 & 0.125 \\
\hline VI & 0.1325 & 0.144 & 0.213 & 0.0402 & 0.102 & 0.22 & 0.060 & 0.077 & 0.155 \\
\hline VII & 0.164 & 0.178 & 0.214 & 0.0525 & 0.125 & 0.21 & 0.07 & 0.054 & 0.141 \\
\hline VIII & 0.125 & 0.111 & 0.298 & 0.043 & 0.119 & 0.27 & 0.07 & 0.043 & 0.161 \\
\hline Mean Value & 0.156 & 0.173 & 0.242 & 0.0126 & 0.2134 & 0.24 & 0.077 & 0.098 & 0.151 \\
\hline
\end{tabular}

\section{CONCLUSION}

In this work various algorithms were applied into the WEKA tool like J48, BN, NB, One R, RT, DS, LR, MLP and SMO optimization for getting the semester wise performance of the students. The algorithms concentrated on the accuracy and error measured parameters. In our analysis, we considered accuracy parameters like time taken to build the model, correctly classified instances and used error measurement parameters like Root mean square error, kappa statistics and mean absolute error. The analysis results in the best algorithm based on accuracy, lowest error rate and time required to build a model. From the above tables it is proved that J48 algorithm is best among the considered algorithms.

\section{References}

[1] Rakesh Mora. A Survey from on data mining in education, JATIT, Vol. 32, 2010, 125-131.

[2] Ester M, Kriegel HP, Sander J, Xu X. A density-based algorithm for discovering clusters in large spatial databases with noise. In: Paper presented at International conference on knowledge discovery and data mining. 1996

[3] Han J, Kamber M. Data mining: concepts and techniques. Massachusetts: Morgan Kaufmann Publishers; 2001.

[4] Ravi Shankar. Institutional Research Using Data Mining, IJACSE, Vol. 132, 2015, 69-81.

[5] Ranny Tigery. Education emphasis in data mining, Journal of Neural Networks,2015, Vol.17,315-323

[6] Berkhin P. A survey of clustering data mining technique. In: Kogan J, Nicholas C, Teboulle M, editors. Grouping multidimensional data. Berlin: Springer; 2006. p. 25-72.

[7] DeLong, C., P. Radclie, L. Gorny. Recruiting for Retention: Using Data Mining and Machine Learning to Leverage the Admissions Process for Improved Freshman Retention. - In: Proc. of the Nat. Symposium on Student Retention, 2007.

[8] B.M. Patil, Hybrid prediction model. Expert Systems with Applications 37 (2010) 8102-8108.

[9] M. A. Khan, W. Gharibi and S. K. Pradhan, "Data mining techniques for business intelligence in educational system: A case mining," 2014 World Congress on Computer Applications and Information Systems (WCCAIS), Hammamet, 2014, pp. 1-5, doi: 10.1109/WCCAIS.2014.6916559.

[10] P. Guleria, M. Arora and M. Sood, "Increasing quality of education using educational data mining," 2013 2nd International Conference on Information Management in the Knowledge Economy, Chandigarh, 2013, pp. 118-122.

[11] T. N. Manjunath, Ravindra S. Hegadi, I. M. Umesh and G. K. Ravikumar, "Realistic Analysis of Data Warehousing and Data Mining Application in Education Domain", International Journal of Machine Learning and Computing, vol. 2, no. 4, August 2012. 
[12] Murtadha M. Hamad and Shumos T. Hammadi, "Quality Assurance Evaluation For Higher Education Institutions Using Statistical Models", International Journal of Database Management Systems (IJDMS), vol. 3, no. 3, August 2011.

[13] G. Satyanarayana Reddy et al., "Data Warehousing Data Mining OLAP And OLTP Technologies Are Essential Elements To Support Decision-Making Process In Industries", (IJCSE) International Journal on Computer Science and Engineering, vol. 02, no. 09, pp. 2865-2873, 2010. 